Bull. Mater. Sci., Vol. 14, No. 6, December 1991, pp. 1309-1322. (C) Printed in India.

\title{
Influence of vanadium on grain boundary segregation of phosphorus in iron and iron-carbon alloys
}

\author{
R D K MISRA \\ Defence Metallurgical Research Laboratory, P.O. Kanchanbagh, Hyderabad 500258 , \\ India \\ MS received 24 June 1991; revised 8 July 1991
}

\begin{abstract}
The influence of vanadium on grain boundary segregation of phosphorus has been studied in iron and iron-carbon alloys by means of fracture experiments in a scanning Auger microprobe. The emphasis here is to study the effects of vanadium on the interaction processes operative under circumstances when structure in the interior of the grain (in the present case carbide formation) and grain boundary segregation form simultaneously. It is emphasized that to predict and analyse the behaviour of an alloy, it is important to consider atomic interactions both at the grain boundaries and in the grain interior and that between the constituents and the grain boundaries. The study suggests that the principal determining factor in the scavenging or retardation of migration of phosphorus to the grain boundaries is whether vanadium is present in the combined form (say, carbide) or is available in solid solution form. When vanadium is present in solid solution form, grain boundary segregation of phosphorus is low because of the chemical interaction of vanadium and phosphorus. However, as carbon is increasingly introduced in the alloy, vanadium now preferentially reacts with carbon in view of higher interaction for carbon as compared to phosphorus. A consequence of this is the increase in the grain boundary concentration of phosphorus. In such a situation the presence of excess carbon in addition to what is stoichiometrically required to precipitate the entire vanadium as vanadium carbides, serves as a palliative with regard to the reduction in the intergranular concentration of phosphorus. This palliative behaviour is explained in terms of the sitecompetition model. An effort is also made to examine the behaviour of segregating elements in terms of whole range of probable interactions (both at the grain boundaries and in the grain interior) and chemical interaction energies.
\end{abstract}

Keywords. Grain boundary segregation; vanadium; phosphorus; carbon; site-competition; Auger electron spectroscopy.

\section{Introduction}

It is generally believed that in addition to carbide precipitation, carbide-forming and some alloying elements profoundly affect grain boundary segregation and the associated interaction processes involving solute and trace elements (the term "trace element" includes both unintentional impurities and intentional microalloying additions). They may enhance or suppress segregation depending on the positive and negative interaction between them and the trace elements. Carbide-forming elements have been observed not to segregate independently at the grain boundaries; they may, however, cosegregate with a trace element, if the interaction energy between them is high (Misra et al 1987b; Misra and Balasubramanian 1989, 1990a, b; Misra and Rama Rao 1991). In such a situation a two-dimensional phase, of the type $M_{p} I_{q}$, may form, where $M$ is the carbide-forming element and $I$ the trace element. Clusters of $M$ and $I$ may also form or a "repulsive interaction" between $M$ and $I$ may result (Guttmann and Mclean 1979; Ustinovshchikov 1983). The nature 
of interactions thus defines the degree of embrittlement and their effect on mechanical properties, in particular, toughness (Misra et al 1986a, b, 1987a; Misra and Rama Rao 1990).

Molybdenum is a classical example of carbide-forming element which is often added to alloy steels to suppress phosphorus segregation and thereby reduce the temper embrittlement to a minimum. The beneficial effect of molybdenum is attributed to the retention of phosphorus atoms in solid solution because of the high interaction energy between molybdenum and phosphorus (Misra et al 1986b; Hondros and Seah 1983). It was, however, noted that the remedial effect of molybdenum is lost on prolonged high temperature aging because of the formation of $\mathrm{Mo}_{2} \mathrm{C}$ carbides, a process which releases scavenged phosphorus back to grain boundaries (McMahon et al 1977). A similar effect is noted when the molybdenum concentration in the steel exceeds approximately $0.7 \mathrm{wt} \%$; there is precipitation of $\mathrm{Mo}_{2} \mathrm{C}$ and consequent depletion of molybdenum in solid solution leading to grain boundary segregation of phosphorus (Yu and McMahon 1980; Dumoulin et al 1980). As regards the behaviour of chromium (another carbide-forming element), synergistic cosegregation of chromium and phosphorus is the only explanation of embrittlement (Ustinovshchikov 1983). In recent years, there is a renewal of interest with regard to the effects of carbide-forming elements on grain boundary segregation processes (Erhart et al 1983; Möller et al 1986; Menyhard and McMahon 1989) particularly in view of their strong influence on interaction processes and mechanical behaviour of metals and alloys (Misra et al 1986a, b). Vanadium which is also a strong carbide former and is commonly added in steels as a microalloying element for varying reasons (e.g. grain refinement, precipitation hardening etc.) does not appear to have received the much deserved attention with regard to grain boundary segregation processes. In a recent study on AISI 4330 steel containing vanadium, the interaction of vanadium with phosphorus and nitrogen to form (V-P) and (V-N) complexes respectively appears to contain a basis for explaining the uncommon beneficial effect of upper bainite on toughness in upper bainite-martensite mixed microstructure (Narasimha Rao et al 1990). Considering the aforementioned characteristics of vanadium as a carbide former and as an element which has significant bearing on mechanical properties (in particular toughness), the present study is an attempt to examine how vanadium influences grain boundary segregation and the associated interaction processes in simple multicomponent systems.

\section{Experimental}

Fe-V-P and Fe-V-C-P alloys were prepared by melting the charge in a water-cooled crucible, in the form of approximately $50 \mathrm{~mm}$ dia. buttons, in a non-consumable vacuum arc melting furnace. Virgin metals of high purity were used in the preparation of alloys. The charges for the alloys were calculated on the basis of $\mathrm{wt} \%$ of alloying elements. The charge was placed at the bottom of the hearth of a water-cooled copper crucible. The furnace was evacuated to $0.133 \mathrm{~Pa}$ and refilled with argon of IOLAR 2 grade containing less than 4 ppm oxygen. The argon flushing cycle was carried out three times to completely remove any residual air in the furnace chamber. In the final cycle the argon pressure was adjusted to $5.3 \times 10^{4} \mathrm{~Pa}$. 
The arc was initiated between the thoriated tungsten electrode and the charge at a current of $500 \mathrm{~A}$ with the help of high-frequency ignition. The molten pool was slowly built-up and the magnetic coil was then switched on to induce circulation of the liquid. The alloy was then cooled to room temperature. After each melting, alloys thus obtained were turned over and the melting procedure repeated twice to ensure chemical homogeneity of the alloys. The chemical composition of the alloys is listed in tables 1 and 2.

To study the effect of vanadium content on the grain boundary segregation of phosphorus, the vanadium content was varied between 0.05 and $0.30 \%$, and the phosphorus content was at about the same level at $0 \cdot 12 \%$. The phosphorus content of $0.12 \mathrm{wt} \%$ in Fe-V-P with $0.2 \mathrm{wt} \%$ vanadium corresponds approximately to the stoichiometric composition of vanadium phosphide. These alloys were decarburized by subjecting them in dry hydrogen atmosphere at $1273 \mathrm{~K}$ for about an hour.

Interactions amongst vanadium, carbon and phosphorus were studied by preparing another series of Fe-V-C-P alloys with wt\% carbon varying from approximately 0.01 to 0.08 . These alloys contained almost similar vanadium content $(\sim 0.2 \mathrm{wt} \%)$ and phosphorus concentration $(\sim 0.12 \mathrm{wt} \%)$. (The stoichiometric carbon required to precipitate entire vanadium of $\sim 0.2 \mathrm{wt} \%$ as VC was $\sim 0.05 \mathrm{wt} \%$.) The two series of alloys were first austenitized at $1323 \mathrm{~K}$ for $2 \mathrm{~h}$ and then water quenched. They were subsequently aged at $823 \mathrm{~K}$ for $24 \mathrm{~h}$.

The specimens for the study of grain boundary chemistry by Auger electron spectroscopy (AES) were prepared from the above basic heat-treated alloys machined to AES fracture specimen geometry (figure 1). In figure 1, notch-1 is the primary notch meant for grain boundary fracture studies and notch-2 acts as a supporting notch for the specimen on the fracture stage. Fresh fracture surfaces were obtained by impacting notched sample (figure 1) at liquid nitrogen temperature within the ultrahigh vacuum $\left(<10^{-7} \mathrm{~Pa}\right)$ system of the Auger electron spectrometer. The fracture surface of the specimen was then positioned in front of the analyser for analysis.

A primary electron beam of $3 \mathrm{keV}$ and a target current of $0.5 \mu \mathrm{A}$ was used. A peak-to-peak amplitude of $3 \mathrm{eV}$ at a frequency of $10 \mathrm{kHz}$ was applied to the

Table 1. Chemical composition of Fe-V.

$P$ alloys in $w t \%$.

\begin{tabular}{lc}
\hline Vanadium & Phosphorus \\
\hline 0.05 & 0.115 \\
0.11 & 0.125 \\
0.20 & 0.120 \\
0.30 & 0.120 \\
\hline
\end{tabular}

Table 2. Chemical composition of Fe-V-P-C alloys in wt \%.

\begin{tabular}{lcc}
\hline Vanadium & Carbon & Phosphorus \\
\hline 0.20 & 0.012 & 0.120 \\
0.20 & 0.030 & 0.125 \\
0.19 & 0.052 & 0.125 \\
0.20 & 0.062 & 0.120 \\
0.19 & 0.075 & 0.122 \\
\hline
\end{tabular}




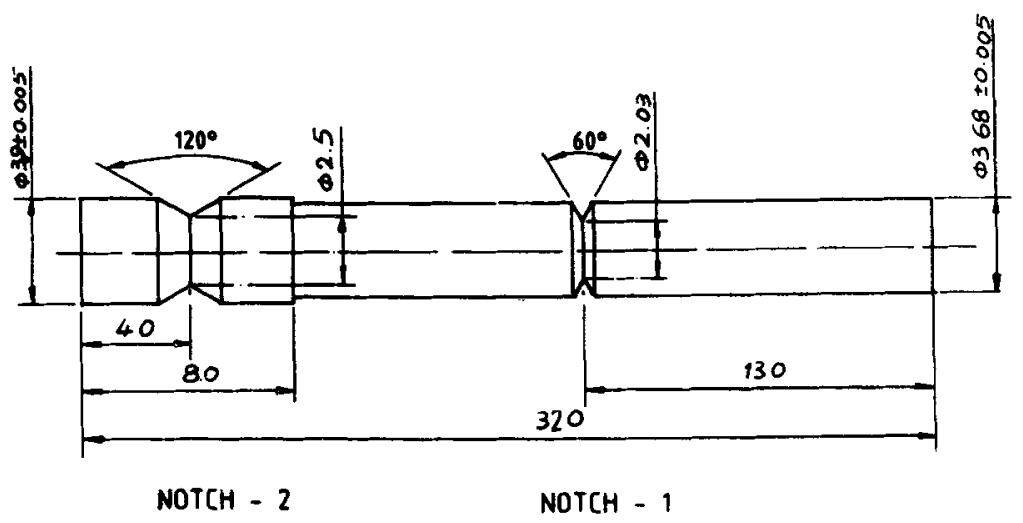

Figure 1. Geometry of AES fracture specimen, all dimensions are in mm. Notch-1 is the primary notch meant for fracture studies, notch-2 acts as a support for the specimen on the fracture stage.

cylindrical mirror analyser for measurement of grain boundary chemical composition. Auger electron peaks analysed were $\mathrm{Fe}(703 \mathrm{eV}), \mathrm{P}(120 \mathrm{eV}), \mathrm{C}(272 \mathrm{eV})$ and $\mathrm{V}(473 \mathrm{eV})$. Auger spectra were recorded in the differentiated mode and peakto-peak heights of the elements were normalised with respect to $\mathrm{Fe}(703 \mathrm{eV})$.

\section{Results and discussion}

An Auger spectrum taken from the intergranular fracture surface in Fe-0.05 V$0.115 \mathrm{P}$ alloy is presented in figure 2 indicating the presence of phosphorus at the grain boundaries. The presence of phosphorus was observed at the grain boundaries in all Fe-V-P alloys. The effect of vanadium concentration in the alloy on the grain boundary segregation of phosphorus in Fe-V-P alloys is summarized in figure 3 where the data are presented in terms of normalized peak-to-peak height (normalized with respect to iron). The underlying objectives for normalizing with respect to the base metal iron are, (i) to eliminate/minimize any ambiguities in the quantification procedure, (ii) to bring out any dependence of grain boundary segregation on the crystallographic orientation of the grain (the grain boundary energy being anisotropic) and the grain boundary structure and (iii) enable a comparative evaluation to be made. In view of the aforementioned reasons, an inevitable scatter in the data is expected; thus instead of mean values, the range over which the values were measured is indicated in the form of bars in figure 3. For each heat-treated sample a number of grain boundaries were studied (at least four locations on each grain boundary fracture surface). Figure 3 shows that the grain boundary concentration of phosphorus decreases with increase in bulk vanadium concentration. The reason for such a behaviour can be explained as due to the locking-up of phosphorus atoms by the vanadium present in solid solution because of high interaction energy of vanadium for phosphorus. The formation of 


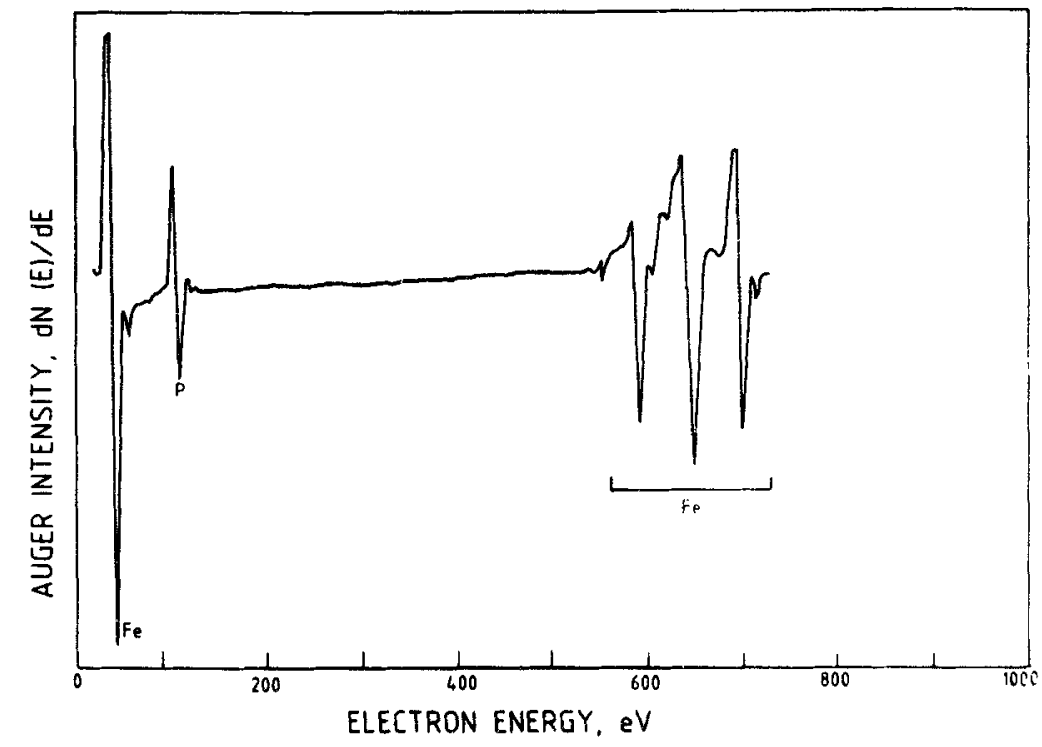

Figure 2. Auger spectrum of intergranular fracture surface in Fe-0.05 V-0.115 P alloy.

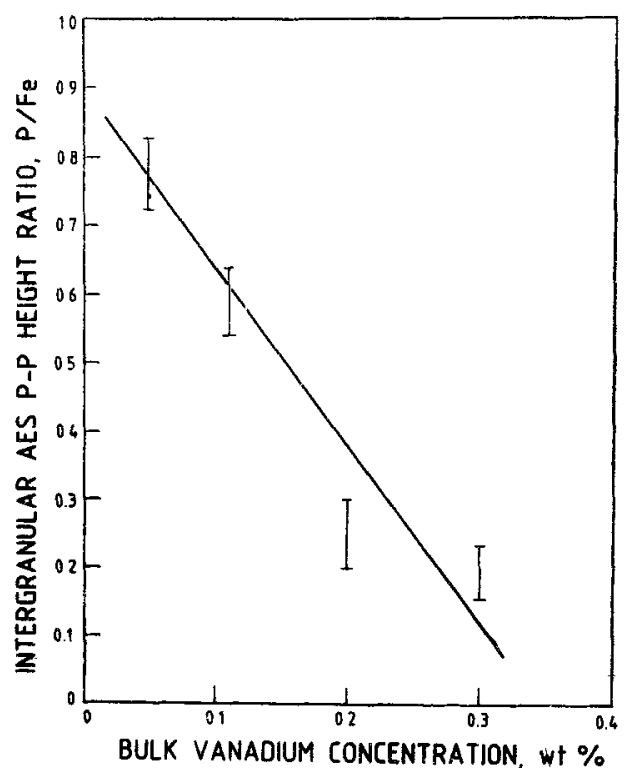

Figure 3. Intergranular concentration of phosphorus as a function of bulk concentration of vanadium in Fe-V-P alloys.

(V-P) complexes or clusters is most likely to be expected during aging at $823 \mathrm{~K}$. This process suppresses the diffusion of phosphorus to the grain boundaries. When sufficient vanadium is present in the solid solution, as in the case of Fe-V-P alloys with 0.2 and $0.3 \mathrm{wt} \%$ vanadium, the grain boundary concentration of phosphorus is very low. It may, however, be noted, from figure 3 that the grain boundary segregation of phosphorus in small concentrations is still observed in alloys 
containing sufficient vanadium (Fe-0.2 V-0.12 P) or even excess vanadium (Fe$0.3 \mathrm{~V}-0.12 \mathrm{P})$ to retain all of the phosphorus atoms in the solid solution. This immediately suggests two possibilities. First, the process of formation of (V-P) complexes or clusters does not undergo completion in the time period for which the alloy is aged at $823 \mathrm{~K}$. The second possibility is that (V-P) complexes or clusters exhibit a range of solubility products $\left([\mathrm{V}]_{x}[\mathrm{P}]_{y}=k\right)$ at the aging temperature of $823 \mathrm{~K}$, such that the nature of complex formed preferably depends on the size of the complex and probably also on the rate of formation (Möller and Grabke 1984). In such a situation, complexes or clusters of (V-P) are formed which contain vanadium atoms in excess of that defined by the stoichiometry, in other words, instead of a complex corresponding (VP) stoichiometry, $V_{x} P(x>1)$ are formed.

The grain boundary segregation behaviour of phosphorus and carbon in Fe-V-P$\mathrm{C}$ alloys is presented in figure 4. In these alloys, vanadium and phosphorus concentration was about the same level $(\sim 0.2 \mathrm{wt} \% \mathrm{~V}$ and $\sim 0.12 \mathrm{wt} \% \mathrm{P})$. The carbon concentration in figure $4 \mathrm{a}$ corresponds to the level measured from the first Auger spectrum recorded soon after the fracture of the sample. Our experience suggests that the low value of measured grain boundary carbon concentration for alloys containing less than $0.052 \mathrm{wt} \%$ carbon pertains to the contamination from the vacuum system before the first Auger spectra is recorded and therefore needs to be ignored. In alloys with $\gtrsim 0.052 \mathrm{wt} \%$ carbon, the contamination of carbon from

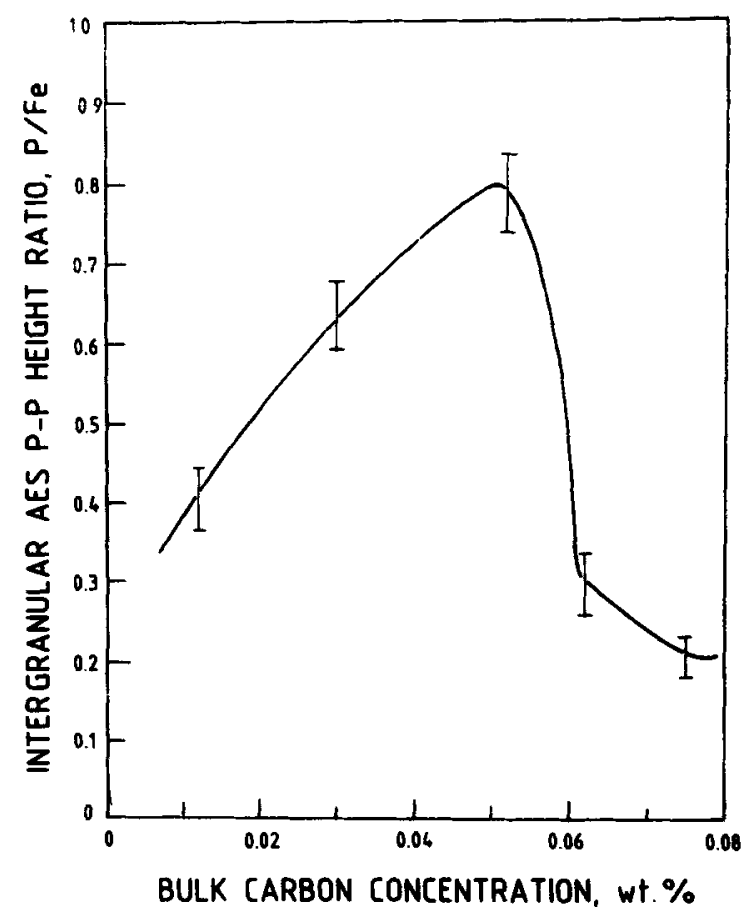

Figure 4. (a) Intergranular concentration of carbon as a function of bulk concentration of carbon in Fe-V-P-C alloys (solid line corresponds to the intergranular carbon concentration determined from the first Auger spectrum recorded soon after fracture. This concentration represents both the contamination from the vacuum system and the true grain boundary carbon segregation. Broken line represents the true intergranular carbon concentration, determined after deduction of contamination level). 


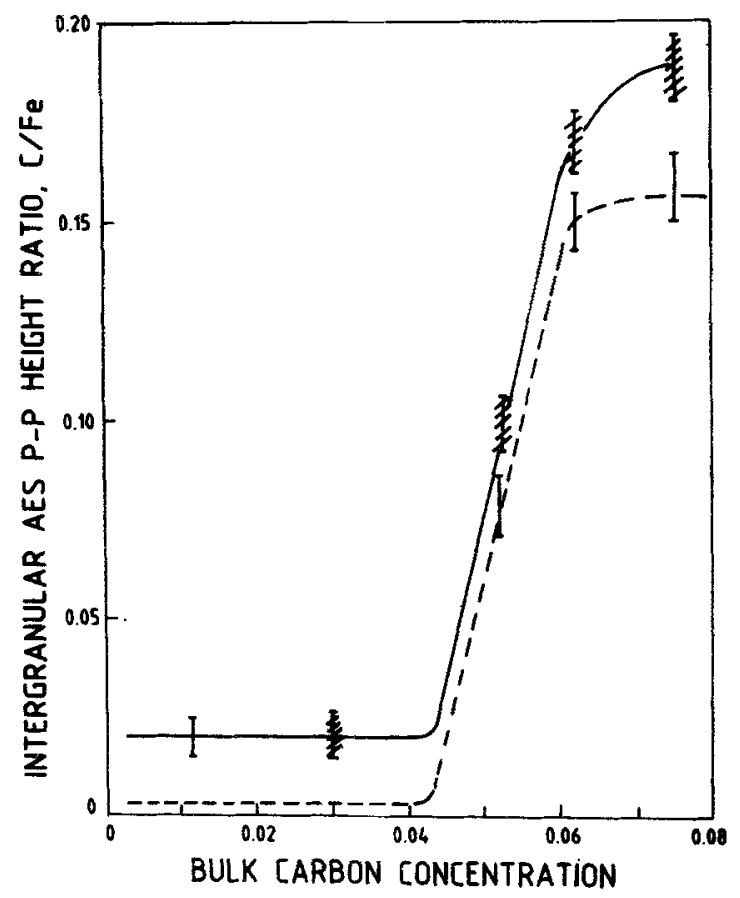

Figure 4. (b) Intergranular concentration of phosphorus as a function of bulk concentration of carbon in Fe-V-P-C alloys.

the vacuum system is subtracted from the measured values (solid line, filled circles) and replotted to obtain true values of grain boundary carbon concentration (broken line, unfilled circles). Thus the values indicated by the unfilled circles are true representative of the carbon segregation process. It may be seen from figure $4 b$ that grain boundary segregation of phosphorus is low for the alloy with lower concentration of carbon $(\sim 0.01)$. With subsequent increase of bulk carbon concentration in the alloy, the grain boundary concentration of phosphorus increases. The increase of grain boundary phosphorus concentration with increase in bulk carbon concentration in Fe-V-C-P alloys can be explained on the basis of (V-C) and (V-P) interactions. It may be noted that the interaction energy between carbide-forming elements and carbon is considerably greater as compared to the interaction energy between the former and phosphorus. Thus, in a situation when carbides form (in the present case VC), the carbide-forming element is depleted from the solid solution and phosphorus segregation increases. The increase of grain boundary phosphorus concentration is a maximum at a carbon concentration of $0.052 \mathrm{wt} \%$. This carbon concentration of 0.052 corresponds approximately to the value required to precipitate all of vanadium as vanadium carbide. An X-ray line profile of carbon and vanadium taken across the grain implies formation of vanadium carbide (figure 5). In $\mathrm{Fe}-0.19 \mathrm{~V}-0.12 \mathrm{P}-0.052 \mathrm{C}$ alloy, vanadium is almost depleted from solid solution and there is thus practically no availability of vanadium atoms for suppressing the diffusion of phosphorus to the grain boundaries.

In alloys with carbon concentration greater than $\sim 0.052 \mathrm{wt} \%$ the presence of 


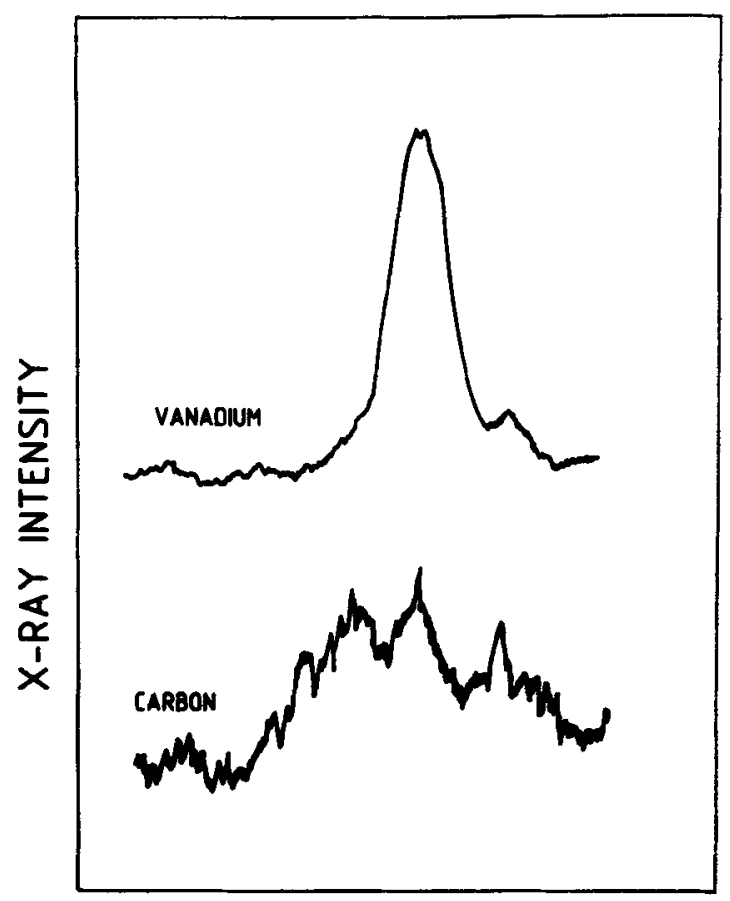

Figure 5. X-ray line profile of carbon and vanadium taken across the grain implying formation of vanadium carbide in Fe-V-C.P alloys.

excess or free dissolved carbon effectively displaces phosphorus from grain boundaries such that the grain boundary concentration of phosphorus is drastically reduced. In addition to this effect, the presence of carbon at the grain boundary is expected to enhance grain boundary cohesion.

The effective displacement of grain boundary phosphorus segregation by carbon in Fe-V-C-P alloys containing greater than $0.052 \mathrm{wt} \%$ carbon can be explained in terms of the site-competition model as described below. The grain boundary coverage of phosphprus $\left(\theta_{\mathrm{p}}\right)$ and carbon $\left(\theta_{\mathrm{C}}\right)$ according to the site-competition model are given by equations (1) and (2) respectively

$$
\begin{aligned}
& \theta_{\mathrm{P}}=x_{\mathrm{P}}\left(1-\theta_{\mathrm{P}}-\theta_{\mathrm{C}}\right) \exp \left(\Delta E_{\mathrm{P}} / k T\right), \\
& \theta_{\mathrm{C}}=x_{\mathrm{C}}\left(1-\theta_{\mathrm{P}}-\theta_{\mathrm{C}}\right) \exp \left(\Delta E_{\mathrm{C}} / k T\right),
\end{aligned}
$$

where $x_{\mathrm{P}}$ and $x_{\mathrm{C}}$ are the bulk concentrations of phosphorus and carbon, respectively. $\Delta E_{\mathrm{p}}$ and $\Delta E_{\mathrm{C}}$ are the segregation energies of phosphorus and carbon. In (1) and (2) only the competition of phosphorus and carbon for sites in the grain boundaries is considered; no energetic interaction between the free dissolved carbon and phosphorus is considered. The fact that thermodynamic measurements for ferrite have not shown any considerable effects on the respective solubilities of carbon and phosphorus (Erhart and Grabke 1981), the neglect of energetic interaction between carbon and phosphorus seems reasonable. The values of $\Delta E_{\mathrm{P}}$ and $\Delta E_{\mathrm{C}}$ are estimated to be 50 and $80 \mathrm{~kJ} / \mathrm{mol}$ (entropy of segregation is neglected) (Erhart and Grabke 1981; Clayton and Knott 1982). 
The temperature dependence of grain boundary phosphorus and carbon segregation for the investigated iron-carbon alloys as derived from (1) and (2) is plotted in figure 6. The degree of carbon segregation decreases with temperature and increases with the available free carbon concentration. Phosphorus, on the other hand, attains a maxima and then decreases with temperature. The magnitude of phosphorus segregation decreases with increase in the available free carbon. The high value of carbon segregation at low temperatures is a consequence of the high segregation energy of carbon. The values of grain boundary coverage of phosphorus and carbon derived from figure 6 for the temperature of interest $(823 \mathrm{~K})$ are plotted in figure 7 , where the experimental values of carbon and phosphorus segregation corresponding to the site-competition regime in figure 4 are also plotted after appropriate conversion of the Auger peak-height ratios to grain boundary coverage. The relation between phosphorus and carbon is comparable to the experimentally observed values. It can therefore be concluded that the site-competition model appropriately describes the behaviour of grain boundary segregation of carbon and phosphorus for Fe-V-C-P alloys containing greater than $\sim 0.052 \mathrm{wt} \%$ carbon.

Niobium has also been observed to act as a scavenger for phosphorus. No evidence of grain boundary segregation was observed by AES on the addition of $0.3 \mathrm{wt} \%$ niobium to a $0.035 \mathrm{wt} \%$ low carbon steel containing $3.49 \mathrm{wt} \% \mathrm{Ni}$, $1.47 \mathrm{wt} \% \mathrm{Cr}$ and $0.05 \mathrm{wt} \% \mathrm{P}$ (Yamanaka and Ohmori 1979). In this steel $0.035 \mathrm{wt} \%$ carbon was able to combine with no more than $\sim 0.25 \mathrm{wt} \%$ niobium. The remaining niobium $(0.05 \mathrm{wt} \%)$ in solid solution retained phosphorus atoms in solid solution because of its high interaction energy with phosphorus. A similar behaviour of niobium was noted in another recent study by Möller and Grabke (1984). With regard to the behaviour of titanium, Möller and Grabke (1984) mentioned in their paper that in contrast to niobium, grain boundary concentration of phosphorus in fact decreases when $\mathrm{TiC}$ particles are formed due to phosphorus segregation at the interfaces of TiC particles.

An important implication of the present study is that it describes an example where on aging atomic interactions in the grain interior and grain boundary segregation occur simultaneously. In view of the fact that earlier experiences have clearly demonstrated that susceptibility to temper embrittlement depends on carbide precipitation at the grain boundaries and in the grain interior, it is essential that while predicting or analysing the behaviour of a metal or an alloy, not only "M-I grain boundaries" but the whole range of probable atomic interactions be considered. This is even more important when carbide-forming elements, such as Mo and V, are involved as observed in the aforementioned study and described below in terms of chemical interaction energies. A comparison of relative chemical interaction energy of $\mathrm{V}$ and $\mathrm{P}(\mathrm{V}-\mathrm{P})$ with respect to base element Fe (i.e. $\alpha_{\mathrm{V} \text {.P }}^{\prime}=\alpha_{\mathrm{V} \text {-P }}-$ $\alpha_{\mathrm{Fe}-\mathrm{P}}-\alpha_{\mathrm{Fe}-\mathrm{V}}$ ) of $\sim 35 \mathrm{kcal} / \mathrm{mol}$ (Guttmann 1976; Ustinovshchikov 1983) to that of $\mathrm{P}$ atoms and grain boundaries (P-gb) of $\sim 12-14 \mathrm{kcal} / \mathrm{mol}$ (Guttmann 1980; Ustinovshchikov 1983) gives the impression that $\mathrm{V}$ shall retain $\mathrm{P}$ in solid solution and thereby suppress segregation of phosphorus. Now, if we compare interaction energies of V-P $(\mathrm{V}-\mathrm{P}=\sim 34 \mathrm{kcal} / \mathrm{mol})$ and $\mathrm{V}-\mathrm{C} \quad(\mathrm{V}-\mathrm{C}=\sim 100-400 \mathrm{kcal} / \mathrm{mol})$ (Ustinovshchikov 1983) one may conclude that phosphorus shall never carry vanadium to grain boundaries just because VC precipitates in the grain interior. However, we have recently observed V-P interaction at the grain boundaries of low alloy steels (Misra et al 1987; Misra and Balasubramanian 1989; 1990a). The 

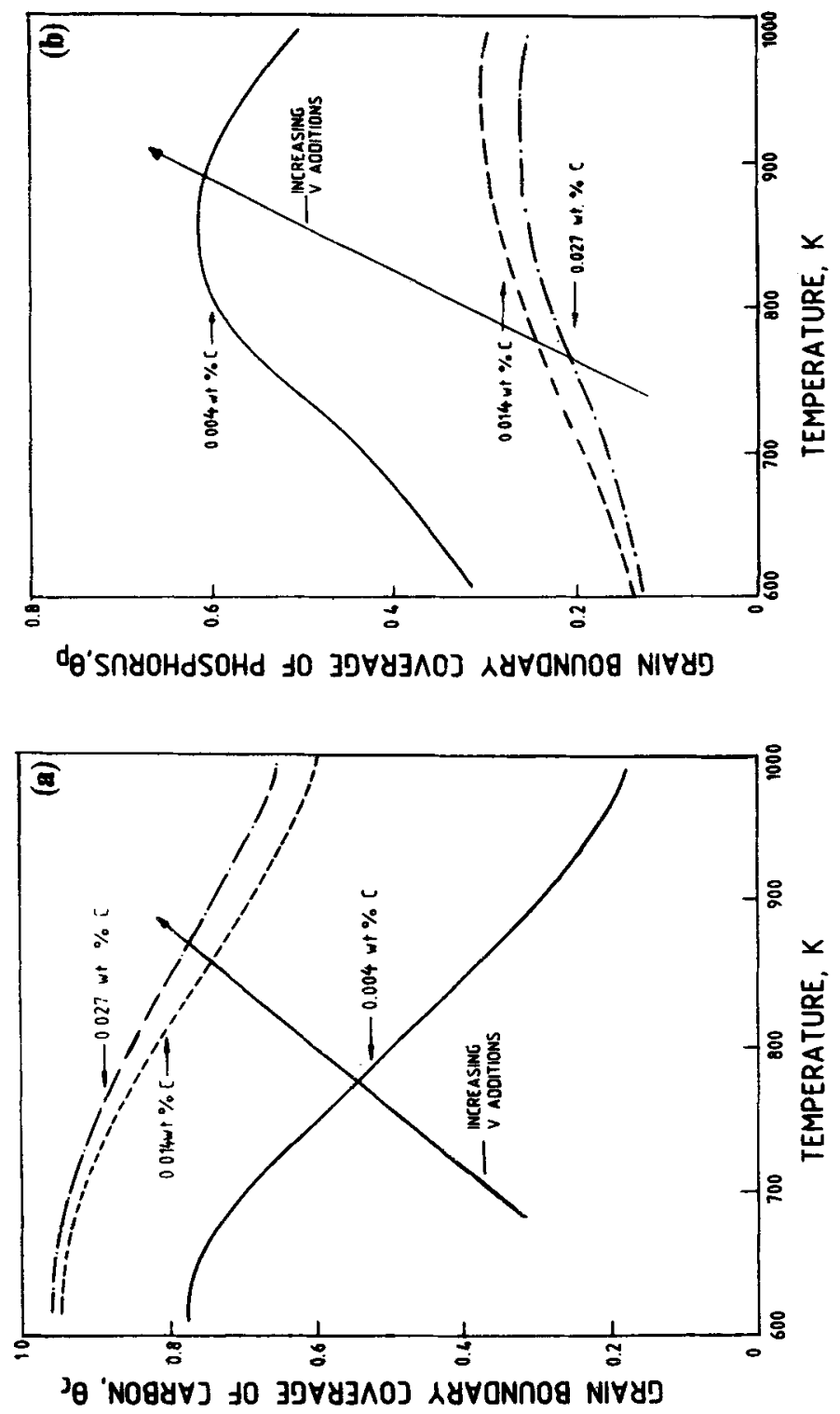

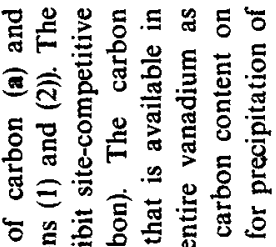

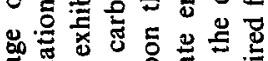

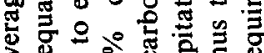

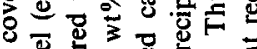

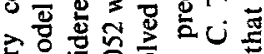

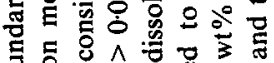
8.

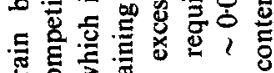

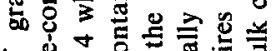

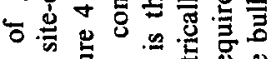


氜 $\Xi$ ส

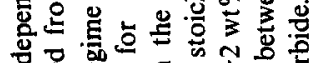
$\times \quad \nabla$

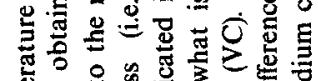

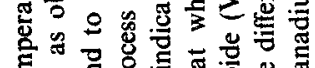

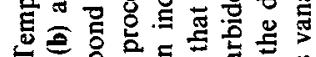
ง

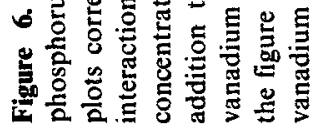




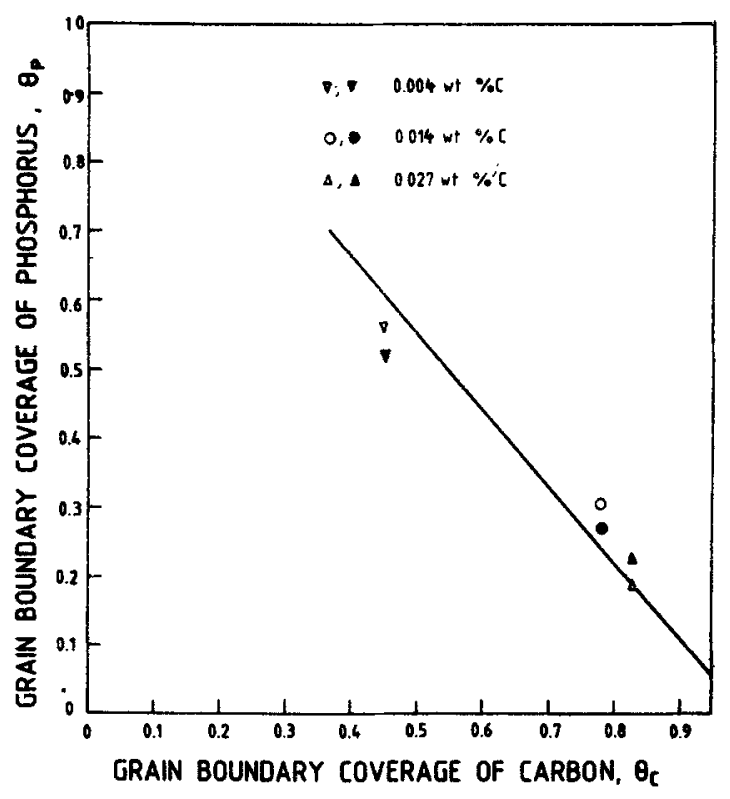

Figure 7. Theoretical (black points) and experimental (white points) values of grain boundary coverage of phosphorus and carbon at $823 \mathrm{~K}$. Theoretical values for the segregation were obtained from figure 6. Experimental values were obtained by appropriately converting the AES P-P height ratios in figure 4 to the grain boundary coverage. The carbon concentration indicated in the figure is the excess dissolved carbon that is available in addition to that required for vanadium carbide precipitation.

observation of grain boundary V-P interaction in low-alloy steels and the V-P interaction in grain interior in the present study may imply that before vanadium carbide is formed, vanadium atoms are statistically distributed in solid solution or form clusters, in both cases the phosphorus atoms are attracted to vanadium atoms resulting in the formation of V-P complexes. When carbides form, phosphorus atoms are free to diffuse to grain boundaries. In conclusion, we wish to emphasize here that the ability of carbide-forming elements to retain or suppress diffusion of embrittling element such as phosphorus in the matrix should not be disregarded, even in a situation where carbides form in the grain interior. In other words, on tempering, it does not necessarily imply that carbide-forming elements if present in solid solution will not retain embrittling element like phosphorus in solid solution, once precipitation has commenced or has entered the final stages of completion. Any presence of dissolved vanadium can retain phosphorus atoms in solid solution, reducing the free energy of segregation and suppressing grain boundary segregation of phosphorus (or any other embrittling element for which it possesses high energy of interaction). A summary of the possible effects of vanadium on the grain boundary segregation of phosphorus is presented in table 3. It may be of relevance to indicate here that the interaction of vanadium with impurity elements, such as, phosphorus and nitrogen to form (V-P) and (V-N) complexes respectively in the matrix has recently been invoked because they were thought to possibly contain one of the arguments for explaining the uncommon beneficial effect of upper bainite on fracture toughness in an upper bainite-martensite mixed microstructure (Narasimha Rao et al 1990). 


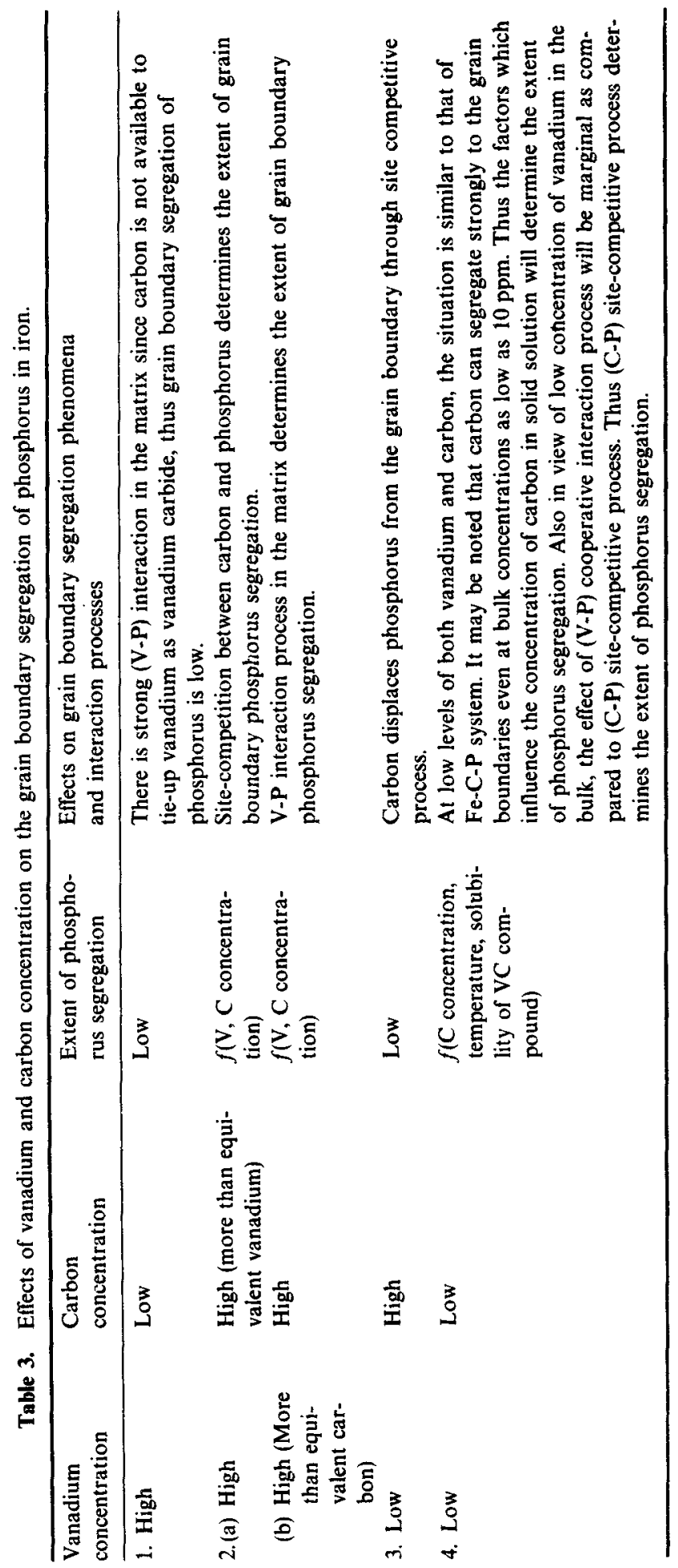




\section{Conclusions}

Interactions amongst solute and trace elements at the grain boundaries and in the grain interior have been studied in Fe-V-P and Fe-V-P-C alloys. The presence of vanadium in solid solution leads to a decrease in the grain boundary segregation of phosphorus because of strong interaction of vanadium and phosphorus. The grain boundary concentration of phosphorus decreases with increase in the bulk vanadium content in Fe-V-P alloy. On tempering of Fe-V-P alloy at $823 \mathrm{~K}, \mathrm{~V}_{x} \mathrm{P}$ complexes or clusters are formed in the matrix.

The introduction of carbon in Fe-V-P alloys leads to preferential interaction of vanadium with carbon to form vanadium carbides in view of its higher interaction for carbon in comparison to phosphorus, thereby allowing phosphorus to segregate at the grain boundaries. However, the presence of excess dissolved carbon in addition to what is required for precipitation of vanadium carbide displaces phosphorus from grain boundary site by site-competition process.

\section{Acknowledgements}

The author expresses his sincere gratitude to Dr P Rama Rao for guidance and inspiration in this work and to Mr S L N Acharyulu, and Dr D Banerjee for their encouragement. The valuable help rendered by $\mathrm{Mr} \mathrm{T}$ V Balasubramanian in AES analysis and Dr R L Saha in the preparation of alloys is gratefully acknowledged. Discussions with Dr Martin A Kearns have been of great help in the study presented here.

\section{References}

Clayton J Q and Knott J F 1982 Met. Sci. 16145

Dumoulin Ph, Guttmann M, Foucalt M, Palmier M, Wayman M and Biscondi M 1980 Met. Sci. 141

Erhart H and Grabke H J 1981 Met. Sci. 15401

Erhart H, Grabke H J and Moller R 1983 Arch. Eisenhuttenwes 54285

Guttmann M 1976 Met. Sci. 10337

Guttmann M 1980 Mater. Sci. Engg. 42227

Guttmann $\mathbf{M}$ and Mclean D 1979 in International segregation (eds) W C Johnson and J M Blakely (Ohio: American Society for Metals) p. 261

Hondros E D and Seah M P 1983 in Interfacial and surface microchemistry (eds) R W Cahn and P Haasen (Lausanne, Switzerland: Elsevier Science Publishers) p. 917

McMahon Jr C J, Cianelii A K and Feng.H C 1977 Metall. Trans. A8 1055

Menyhard M and McMahon Jr C J 1989 Acta Metall. 372287

Misra R D K, Prasad C Y. Balasubramanian T V and Rama Rao P 1986a Scr. Metall. 20713

Misra R D K, Prasad C Y, Balasubramanian T V and Rama Rao P 1986b Ser. Metall. 201339

Misra R D K. Prasad C Y, Balasubramanian T V and Rama Rao P 1987a Scr. Metall. 211067

Misra R D K, Balasubramanian T V and Rama Rao P 1987 b Acta Metall. 352995

Misra R D K and Balasubramanian T V 1989 Acta Metall. 371475

Misra R D K and Rama Rao P 1990 Indian J. Technol. 28500

Misra R D K and Balasubramanian T V 1990a Acta Metall. 381263

Misra R D K and Balasubramanian T V 1990b Acta Metall. Mater. 382357

Misra R D K and Rama Rao P 1991 Acta Metall. Mater. 39 in press

Möller R and Grabke H J 1984 Scr. Metall. 18527 
Möller R, Brenner S S and Grabke H J 1986 Scr. Metall. 20587

Narasimha Rao T V L. Dikshit S N, Malakondaiah G and Rama Rao P 1990 Scr. Metall. Mater. 24 1323

Ustinovshchikov J I 1983 Acta Metall. 31355

Yu J and McMahon Jr C J 1980 Metall. Trans. A11 277

Yamanaka K and Ohmori Y 1979 Trans. Iron Steel Inst. Japan 19339 